\title{
Trimmed Placental Weight
}

National Cancer Institute

\section{Source}

National Cancer Institute. Trimmed Placental Weight. NCI Thesaurus. Code C117338.

The weight of the trimmed placenta to the nearest gram, with membranes severed at the disc edge and the umbilical cord cut to within $1 \mathrm{~cm}$ of insertion, after draining the blood from the specimen. 